\title{
Simmental İneklerinde İklimsel Faktörler ile Soğuk Stresinin Davranış Özelliklerine Etkisi []
}

\author{
Akif UYSAL ${ }^{1} \quad$ Emrah KAYGUSUZ ${ }^{2} \quad$ Filiz AKDAĞ ${ }^{1 *}$ \\ ${ }^{l}$ Ondokuz Mayls Üniversitesi, Veteriner Fakültesi, Zootekni Anabilim Dall, Samsun, Türkiye. \\ ${ }^{2}$ Tarım ve Orman Bakanlığı Mezrifon İlçe Müdürlügü̈, Merzifon, Amasya, Türkiye.
}

Atıf yapmak için: Uysal, A., Kaygusuz, E. \& Akdağ, F. (2021). Simmental İneklerinde İklimsel Faktörler ile Soğuk Stresinin Davranış Özelliklerine Etkisi. Anadolu Çev. ve Hay. Dergisi, 6(4), 679-683.

How to cite: Uysal, A., Kaygusuz, E. \& Akdağ, F. (2021). The Effect of Climatic Factors and Cold Stress on Behavioral Traits in Simmental Cows. J. Anatolian Env. and Anim. Sciences, 6(4), 679-683.

*Sorumlu yazarın:

Filiz AKDĂ̆

Ondokuz Mayis Üniversitesi Veteriner

Fakültesi, Zootekni Anabilim Dalı,

Samsun, Türkiye.

凶: filizakdag@omu.edu.tr
Öz: $\mathrm{Bu}$ araştırma, açık barınakta yetiştirilen Simmental ineklerinde iklimsel faktörlerin ve soğuk stresinin bazı davranış özelliklerine etkisini belirlemek amacıyla yapılmıștır. Araştırmada, 24 baş Simmental ineğin kış mevsimi süresince dinlenme, yem yeme, yürüme ve hareketsiz ayakta bekleme gibi davranış özelliklerinin süreleri belirlenmiş ve günlük ortalama çevre sıcaklığı, rüzgar hızı, nem oranı ve yağış miktarı tespit edilerek soğuk stres indeksi hesaplanmıştır. Araştırmada günlük ortalama rüzgar hızı ve çevre sıcaklığının kış mevsiminde farklı aylarda ölçülen değerleri arasındaki farkın önemli $(\mathrm{P}<0,01)$ olduğu belirlenmiştir. Kış mevsimi süresince takip edilen davranış özelliklerinden dinlenme davranışı süresinin aylar arasındaki farkının önemli olduğu $(\mathrm{P}<0,05)$ belirlenmiştir. Araştırmada, iklimsel faktörlerden rüzgar hızı ile dinlenme süresi, çevre sıcaklığı ile yem yeme süresi arasında negatif fenotipik korelasyon $(\mathrm{P}<0,05)$ olduğu belirlenmiştir. Ayrıca, bağıl nem oranı ile dinlenme süresi, yağış miktarı ve soğuk stres indeksi ile yürüme süresi arasında önemli pozitif fenotipik korelasyon tespit edilmiştir $(\mathrm{P}<0,05)$. Sonuç olarak, dinlenme davranışının rüzgar hızının düşük olduğu sıcak dönemlerde daha fazla sürdüğ̈̈, düşük çevre sıcaklığının hayvanların yem yeme süresinde, yağış ve soğuk stresinin ise yürüme süresinde artış meydana getirdiği belirlenmiştir. Ayrıca, süt sığırı yetiştiriciliğinde iklimsel faktörlerin ve soğuk stresinin hayvanlar üzerindeki olumsuz etkilerini giderebilmek için hayvan davranışlarının takip edilerek sürü yönetiminde düzenlemelerin yapılmasının yararlı olacağı sonucuna varılmıştır.

Anahtar kelimeler: Dinlenme davranıșı, rüzgar hızı, simmental, soğuk stres indeksi.

\section{The Effect of Climatic Factors and Cold Stress on Behavioral Traits in Simmental Cows}

*Corresponding author's: Filiz AKDAĞ

Ondokuz Mayis University, Faculty of

Veterinary Medicine, Department of

Animal Science, Samsun, Turkey.

凶: filizakdag@omu.edu.tr

\begin{abstract}
The aim of this study was to determine effect of climatic factors and cold stress on behavioural patterns of Simental cattle kept in free stall barns. In this research, it is calculated that the duration of some beheviour traits of twenty four simmental cows during winter season like having lying down, eating feed, motion behaviour and standing and it is calculated that cold stress indexes of climatic factors like daily avarage ambient temperature, wind speed, humidity and rainfall. In this research, it is determined as significiant that the difference of daily avarage wind speed and environmental temperature $(\mathrm{P}<0.01)$. There were also significant differences in terms of duration of behavioural lying down different months in winter season $(\mathrm{P}<0.05)$. There is a significiant phenotypic correlation between the rate of wind speed and relative humidity lying down, in climatic factors and the duration of eating feed, rainfall end the duration of motion behaviour on cold stress indexes $(\mathrm{P}<0.05)$. As a result, it was observed that the lying down lasted longer in warm periods when the wind speed was low, and it was determined that low environmental temperature caused an increase in the eating feed time of the animals, and rainfall and cold stress caused an increase in the walking time. In addition, in the study, it was concluded that it would be beneficial to make regulations in herd management by monitoring animal behavior in order to eliminate the negative effects of climatic factors and cold stress on animals in dairy cattle breeding.
\end{abstract}

$\underline{\text { Keywords: Cold stress index, lying down, rainfall, simmental. }}$ 


\section{GİRiş}

Soğuk stresi, merada, açık barınaklarda ve yarı açık serbest gezinmeli ahırlarda yetiştirilen süt sığırlarının düşük çevre sıcaklığında karşılaştığı temel çevresel problemlerdendir. Bağıl nem oranı, rüzgâr hızı ve solar radyasyon gibi iklimsel (meteorolojik) özellikler çevre sıcaklığının hissedilme derecesini etkileyerek hayvanlarda soğuk stresinin oluşmasına sebep olmaktadır (Angrecka \& Herbut, 2015; Kaygusuz, 2020). Bu faktörlere eklenen kar, yağmur ve çamur etkenleri ise soğuk stresinin etkisini artırmaktadır (Xu vd., 2017). Barınak koşullarına, hayvanın yaşına, beslenmesine ve kıl yapısına göre kritik düşük çevre sıcaklığı, kar ve rüzgarın olmadığı dış ortamdaki gebe veya kurudaki sütçü sığır ırkları için $-14^{0} \mathrm{C}$ 'dir. Fakat, bu kritik düşük çevre sıcaklığı değeri süt verim seviyesine göre değişerek, günlük süt verimi 30 litre olan laktasyondaki sütçü 1rk ineklerde $-40^{\circ} \mathrm{C}$ gibi daha düşük bir değere inebilmektedir (Kaygusuz, 2020; NRC, 1981).

Sığırlarda soğuk stresinin çeşitli verim özellikleri üzerindeki etkisini belirlemek için çevre sıcaklığı, rüzgar, nem, solar radyasyon ve yağış gibi iklimsel faktörlerden yararlanılarak (Hanninen vd., 2003) rüzgar soğutma indeksi, soğuk stres indeksi ve sığır konfor indeksi gibi bazı indeksler geliştirilmiştir (Davis vd., 2003; Donnely, 1984; Mader vd., 2010; Van Lear vd., 2014). Bu indekslerden, rüzgar soğutma indeksinde çevre sıcaklığı ve rüzgar hızı (Van Lear vd., 2014), soğuk stres indeksinde çevre sıcaklığı, rüzgar hızı ve yağmur değişkeni (Davis vd., 2003; Donelly, 1984), sığır konfor indeksinde ise çevre sıcaklığı, nem, rüzgar hızı ve solar radyasyon değişkenleri kullanılmıştır (Mader vd., 2010). Soğuk stress indeksi, Donelly (1984) tarafindan soğuk stresinin koyunlarda etkisini belirlemek için geliştirilen, fakat ilerleyen zamanlarda özellikle yıl boyunca açıkta otlatılarak yetiştirilen sı̆̆ırlara adepte edilmiş bir indekstir (Bryant vd., 2007; Davis vd. 2003).

Çevre sıcaklığı, kritik düşük sıcaklığının $\left(-14^{0} \mathrm{C}\right)$ altına indiği zaman hayvanlarda soğuğa karşı bir dizi biyolojik tepki gerçekleşmekte (Könyves vd., 2017) ve hayvanların davranış özelliklerinde değişim meydana gelmektedir (Sasaki vd., 2016; Schütz vd., 2010). Hayvanların doğal (normal) davranışları onların sağlığı, refahı, üreme ve üretkenlik durumunun bir göstergesi olarak kabul edilmektedir. Hayvanların davranışları ve bu davranışlarının süreleri ise genetik yapı ile hastalıklar, barınma koşulları, ahır şekli, sürü yoğunluğu, gün ışığının uzunluğu, mevsim ve çevre sıcaklığı gibi birçok faktöre bağlı olarak değişebilmektedir (Tullo vd., 2019). Kış mevsiminde özellikle yoğun yağışlı dönemlerde hayvanlar soğuk stresinin etkisini azaltmak için sıcak, korunaklı ve rahat bir yer bulmaya çalışarak hareketlerini artırırlar (Borshch vd., 2020). Buna karşın, buzlu veya donmuş gübrenin oluşturduğu sert düzensiz yüzeylerde hareket etmek yerine (Endris \& Feki, 2021) daha çok ayakta kalmayı tercih ederler (Schütz vd., 2010). Borshch vd., (2019) kış mevsiminde sı̆̆ır davranışlarında gözlemlenen en önemli değişikliğin dinlenme ve beslenme davranışlarında meydana geldiğini, soğuk strese maruz kalan sı̆̆ırların konfor zonundaki döneme göre dinlenme süresinin azaldığını, yem tüketiminde ise artış oluştuğunu bildirmişlerdir.

$\mathrm{Bu}$ araştırma, sundurmalı açık barınakta yetiştirilen Simmental ineklerinin bazı davranış özelliklerine iklimsel faktörlerin ve soğuk stresinin etkisini belirlemek amacıyla yapılmıştır.

\section{MATERYAL VE METOT}

Araştırma, Amasya ilinin Merzifon ilçesinde, sundurma şeklinde inşa edilmiş hayvan barınakları bulunan, özel bir süt sığırı işletmesinde yürütülmüştür. Araştırmanın hayvan materyali olarak laktasyonun erken döneminde (ilk 100 gün) olan ilk üç laktasyondaki ineklerden eşit sayıda ve tesadüfi olarak seçilen toplam 24 baş Simmental inek kullanılmıştır.

Araştırma için seçilen ineklerin bakım ve beslenme koşullarında herhangi bir değişiklik yapılmamış, işletme koşulları aynen uygulanmıştır. Hayvanların beslenmesinde hayvan başına günlük $10 \mathrm{~kg}$ süt yemi (\%19 ham protein ve 2700 kcal metabololik enerji içeren yem), $24 \mathrm{~kg}$ misır silajı, $3 \mathrm{~kg}$ yonca ve $4 \mathrm{~kg}$ samandan oluşan rasyon kullanılmış ve su ihtiyaçları adlibitum karşılanmıştır.

Araştırmada, kış mevsimi süresince ineklerin dinlenme, yem yeme, ayakta hareketsiz bekleme ve yürüme gibi bazı davranış özellikleri ile iklimsel faktörlerden çevre sıcaklığı, bağıl nem oranı, rüzgar hızı ve yağış miktarı belirlenmiş ve soğuk stres indeksi (Bryant vd., 2007; Davis vd. 2003; Donelly, 1984) hesaplanmıştır.

Davranış özelliklerini belirlemek için aralık, ocak ve şubat aylarında 15 günlük aralıklarla dijital kamera vasıtasıyla hayvan davranışları kaydedilmiştir. Davranış kayıtları için hayvan barınaklarının bulunduğu alanları görecek şekilde iki farklı yere yerleştirilen ve 24 saat kayıt yapan gece görüşlü kamera kullanılmıştır. Davranışların analizi için kış mevsimi süresince 15 gün aralıklarla sabah 07.00 - 07.30, öğlen 12.00-12.30 ve akşam 17.00-17.30 saatleri arasında günlük toplam 1.5 saatlik davranış kayıtlarından dinlenme, yem yeme, hareketsiz ayakta bekleme (ayakta durma) ve yürüme davranışları her bir hayvan için izlenmiş ve bu davranışların süreleri kaydedilmiştir (Graunke vd., 2011; Kaygusuz \& Akdağ 2021).

İklimsel faktörlerin tespiti için süt sığırı işletmesinin bulunduğu ilçenin aralık, ocak ve şubat aylarına ait günlük ortalama kuru termometre sıcaklığı, bağıl nem oranı, rüzgar hızı ve yağış miktarı değerleri Merzifon Meteoroloji İstasyon Müdürlüğünden temin edilmiştir. Soğuk stresin hayvanlar üzerindeki etkisini belirlemek için 
Donelly, (1984) tarafindan geliştirilen soğuk stres indeksinden (CSI; cold stress index)yararlanılmıştır (Bryant vd., 2007; Davis vd. 2003; Donelly, 1984). Soğuk stres indeksinin hesaplanmasinda (CSI) CSI $=[11.7+$ $\left.\left(3.1 \times \mathrm{WS}^{0.5}\right)\right] \times(40-\mathrm{T})+481+\mathrm{R}$ eşitliğinden yararlanılmıştır. Bu eşitlikte;

CSI: soğuk stres indeksi $\left(\mathrm{MJ} / \mathrm{m}^{2} / \mathrm{s}\right)$

WS: günlük ortalama rüzgar hızı $\left(\mathrm{m} / \mathrm{sn}^{-1}\right)$

T: günlük ortalama çevre sicaklığ $\left({ }^{\circ} \mathrm{C}\right)$

$\mathrm{R}=418 \times\left(1-\mathrm{e}^{-0.04 \times \text { rain }}\right)$

$\mathrm{e}^{-}:$doğal loratima $=2,718$

rain: günlük toplam milimetreye düşen yağış miktarın ifade etmektedir.

İstatistiksel Analiz: $\mathrm{Bu}$ araştırmada elde edilen verilerin normal dağılıma uygunlukları, KolmogorovSmirnov testi ile belirlenmiş̧ir. Kış mevsimi süresince günlük ortalama çevre sıcaklığı, bağıl nem oranı, rüzgar hızı, yağış miktarı ve soğuk stres indeksinin aylara göre karşılaştırılmasında tekrarlı ölçümlerde tek yönlü varyans analizi kullanılmış, gruplar arasındaki farkın önem kontrolünde ise Benfori testinden yararlanılmıştır. Farklı aylarda gözlemlenen davranış özelliklerinin sürelerinin karşılaştırılmasında ise en küçük kareler yöntemi kullanılmış ve gruplar arasındaki farkın önem kontrolünde Duncan testinden yararlanılmıştır. Ayrıca, soğuk stres indeksi ve iklimsel faktörlerin davranış özellikleriyle arasındaki ilişkiyi belirleyebilmek için pearson korrelasyon testi uygulanmıştır. Tüm istatistiksel hesaplamalarda SPSS 21v. program paketinden (IBM Corporation, Armonck, NY) yararlanılmıştır.

\section{BULGULAR}

İklimsel faktörler ve soğuk stres indeksinin aylara göre ortalama değer ve standart hataları Tablo 1'de verilmiștir. İklimsel faktörlerden rüzgar hızı ve çevre sıcaklığının kış mevsiminde farklı aylarda ölçülen günlük

ortalama değerleri arasındaki fark önemli $(\mathrm{P}<0.05)$ olarak belirlenmiştir. Simmental ineklerinde kış mevsiminde gözlemlenen bazı davranış özelliklerinin sürelerine ait ortalama değer ve standart hataları Tablo 2'de verilmiş̧tir. Davranış özelliklerinin farklı aylara göre karşılaştırılmasında, sadece dinlenme davranış süresinin aylar arasındaki farkının önemli olduğu $(\mathrm{P}<0,05)$ belirlenmiştir.

Davranış özellikleri ile iklimsel faktörler ve soğuk stres indeksi arasındaki fenotipik korelasyon katsayıları Tablo 3'de verilmiştir. Davranış özelliklerinden dinlenme süresinin rüzgar hızı $(\mathrm{P}<0,05)$ ve bağıl nem oranıla $(\mathrm{P}<0,01)$; yem yeme süresinin çevre sıcaklığıyla $(\mathrm{P}<0,05)$, yürüme süresinin ise yağı̧ miktarıyla arasında önemli $(\mathrm{P}<0,05)$ fenotipik korelasyona sahip olduğu belirlenmiștir $(\mathrm{P}<0,05)$. Soğuk stres indeksinin ise hayvan davranışlarından sadece yürüme davranışı ile arasında önemli seviyede fenotipik korelasyon olduğu $(\mathrm{P}<0,05)$ tespit edilmiştir.

Tablo 1. İklimsel faktörlerin kış mevsimine ait ortalama değer ve standart hataları $(\overline{\mathrm{x}} \pm \mathrm{S} x)$.

Table 1. Mean values and standard errors of climatic factors in the winter $\left(\overline{\mathrm{x}} \pm \mathrm{S}_{\overline{\mathrm{x}}}\right)$.

\begin{tabular}{lcccc} 
Özellikler & Aralık & Ocak & Şubat & P değeri \\
\hline Rüzgar hızı $(\mathrm{m} / \mathrm{sn})$ & $1,08 \pm 0,09 \mathrm{~b}$ & $0,75 \pm 0,09 \mathrm{~b}$ & $1,47 \pm 0,10 \mathrm{a}$ & 0,001 \\
Çevre sıcaklığ $\left.1{ }^{\circ} \mathrm{C}\right)$ & $4,67 \pm 0,52 \mathrm{a}$ & $1,59 \pm 0,38 \mathrm{~b}$ & $3,12 \pm 0,82 \mathrm{ab}$ & 0,003 \\
Bağıl nem oranı $(\%)$ & $72,74 \pm 1,92$ & $73,96 \pm 1,51$ & $67,57 \pm 2,52$ & 0,096 \\
Yağıs miktarı $(\mathrm{kg} / \mathrm{mm})$ & $1,53 \pm 0,64$ & $0,53 \pm 0,20$ & $1,26 \pm 0,69$ & 0,410 \\
SSİ $\left(\mathrm{MJ} / \mathrm{m}^{2} / \mathrm{s}\right)$ & $1027,28 \pm 11,58$ & $1034,67 \pm 7,95$ & $1065,06 \pm 14,64$ & 0,080 \\
\hline a,b: Aynı satırda farklı harflerle gösterilen ortalamalar arasindaki fark önemlidir $(\mathrm{P}<0,05) ;$ SSİ:
\end{tabular}
Soğuk stres indeksi

Tablo 2. Simmental ineklerde bazı davranış özelliklerinin sürelerine (dakika) ait ortalama değer ve standart hatalar $\left(\overline{\mathrm{x}} \pm \mathrm{S}_{\overline{\mathrm{x}}}\right)$.

Table 2. Mean value and standard errors of the duration (minutes) of some behavioral traits in Simmental cows $\left(\overline{\mathrm{x}} \pm \mathrm{S}_{\overline{\mathrm{x}}}\right)$.

\begin{tabular}{lcccc}
\hline Aylar & Dinlenme & Yem yeme & Ayakta bekleme & Yürüme \\
\hline Aralık & $11,49 \pm 1,70 \mathrm{a}$ & $10,30 \pm 1,32$ & $6,23 \pm 1,64$ & $0,16 \pm 0,04$ \\
Ocak & $7,75 \pm 1,21 \mathrm{~b}$ & $9,11 \pm 0,93$ & $9,71 \pm 1,16$ & $0,21 \pm 0,02$ \\
Şubat & $6,93 \pm 1,11 \mathrm{~b}$ & $10,94 \pm 0,86$ & $9,71 \pm 1,07$ & $0,21 \pm 0,02$ \\
P değeri & 0,05 & 0,339 & 0,164 & 0,370 \\
\hline a,b: Aynı sütünda farklı harflerle gösterilen ortalamalar arasındaki fark önemlidir $(\mathrm{P}<0,05)$
\end{tabular}

Tablo 3. Davranış özellikleri ile iklimsel faktörler ve soğuk stres indeksi arasındaki fenotipik korelasyon katsayıları.

Table 3. Phenotypic correlation coefficients among climatic factors and cold stress index and behavioral traits.

\begin{tabular}{lccc}
\hline Özellikler & Dinlenme süresi & Yem yeme süresi & Ayakta kalma süresi \\
\hline Rüzgar hızı & $-0,216^{*}$ & 0,054 & 0,130 \\
Sicaklık & 0,086 & $-0,221^{*}$ & 0,108 \\
Bağı̈l neme süresi & $-0,089$ & $-0,119$ & $-0,098$ \\
Yağış miktarı & $0,278^{* *}$ & $-0,159$ & 0,025 \\
SSİ & 0,075 & 0,114 & 0,064 \\
\hline
\end{tabular}

\section{SONUÇ VE TARTIŞMA}

$\mathrm{Bu}$ araştırmada, kış mevsiminde farklı aylarda ölçülen bağıl nem oranı ve yağış miktarının tüm aylarda birbirine yakın değerlerde gerçekleştiği, çevre sıcaklığının ise aralık ve şubat aylarında $\left(4,67^{\circ} \mathrm{C}-3,12^{\circ} \mathrm{C}\right)$ birbirine yakın fakat ocak ayından daha yüksek olduğu ve rüzgar hızının aralık ayında şubattan daha düşük hıza sahip olduğu belirlenmiştir. Araștırmada elde edilen bulgular, kış mevsiminde tüm aylarda çevre sıcaklığının sütçü sığırlar için bildirilen konfor aralığına yakın değerde gerçekleștiğini, buna karşın iklimsel faktörlerin hayvanlar üzerindeki olumsuz etkilerinin en az hissedildiği dönemin aralık ayı olduğunu göstermektedir. Koç ve Uğurlu, (2019) 
laktasyondaki süt sığırlarının metabolik ve fizyolojik faaliyetlerini yürütebildikleri konfor çevre sıcaklığın $5^{\circ} \mathrm{C}$ $15^{\circ} \mathrm{C}$ arasında olduğunu bildirmişlerdir. Bununla birlikte NRC, (1981) rüzgar, kar ve çamur olmadığı durumlarda dış ortamda yetiştirilen kurudaki sığırlar için kritik düşük çevre sıcaklı̆g 1 değerini $-14^{0} \mathrm{C}$ olarak bildirmiş ve bu değerin laktasyondaki ineklerde süt verim düzeyine göre $40^{\circ} \mathrm{C}$ 'ye kadar inebildiği bildirmiş̧ir. Angrecka \& Herbut, (2015) hayvanların hissettikleri çevre sıcaklı̆̆ında rüzgar, nem ve solar radyasyon gibi çevresel faktörlerin etkili olduğunu bildirmişlerdir. Byrant vd., (2007) sütçü sığırların sıcak havaya oranla soğuğa karşı daha dayanıklı olduklarını ve laktasyonun pik döneminde olan inekler için kritik çevre sıcaklığının kuru çevre koşullarında $-30^{\circ} \mathrm{C}$ olduğunu bildirmiştir. $\mathrm{Bu}$ araştırmanın bir diğer bulgusu olarak soğuk stres indeksi kış mevsimi süresince birbirine yakın değerlerde ve $1027-1065 \mathrm{MJ} / \mathrm{m}^{2} / \mathrm{s}$ aralığında belirlenmiş̧tir. Byrant vd., (2007) Yeni Zelanda da yaptı̆̆ 1 araştırmada 1990-2002 yılları arasında soğuk stres indeksini $746-1457 \mathrm{MJ} / \mathrm{m}^{2} / \mathrm{s}$ değerleri arasında belirlemiş ve süt sığırları için soğuk stres indeksinin üst eşik değerinin $1300 \mathrm{MJ} / \mathrm{m}^{2} / \mathrm{s}$ olarak alınması gerektiğini bildirmişlerdir.

Simmental ineklerin kış mevsimi süresince gözlemlenen bazı davranış özellikleri değerlendirildiğinde, araştırmada hayvanların dinlenme süresinin aralık ayında diğer aylara göre daha fazla sürdüğü tespit edilmiştir. $\mathrm{Bu}$ sonucun, rüzgar hızının düşüklüğüne bağlı olarak çevre sıcaklığının aralık ayında diğer aylara göre daha yüksek hissedilmesinden kaynaklandığı düşünülmektedir. Schütz vd., (2010) Yeni Zelanda da yıl boyunca açıkta otlatılarak yetiştirilen süt sığırlarının rüzgarlı ve rüzgarla birlikte yağışın olduğu zamanlarda dinlenme için harcadıkları sürede azalma olduğunu, kapalı barınaklarda günde 12-15 saat süren dinlenme davranışının açık alanda yetiștirilen sığırlarda 10.0-11.8 saate indiğini bildirmiștir. Borshch vd., (2019) meralarda veya açık barınaklarda soğuk strese maruz kalan sığırların konfor zonundaki döneme göre daha az dinlenme davranışı gösterdiklerini bildirmişlerdir.

$\mathrm{Bu}$ araştırmada davranış özellikleri ile iklimsel faktörler ve soğuk stres indeksi arasında belirlenen fenotipik korrelasyon katsayıları değerlendirildiğinde; dinlenme süresindeki artışın rüzgar hızındaki azalma ve bağıl nem oranındaki artışla, hayvanların yem yeme süresindeki artışın ise çevre sıcaklığındaki düşüşle ilişkili olduğu belirlenmiştir. Tullo vd., (2019) sığırlarda dinlenme süresinin uzunluğunun genellikle daha iyi refah göstergesi olduğunu ve bu davranış üzerinde mevsim, sıcaklık ve ahırın bulunduğu enlem gibi birçok faktörün etkili olduğunu bildirmişlerdir. Schütz vd., (2010) süt sığırlarında iklimsel faktörlerin hayvan davranışları üzerinde etkili olduğunu, yağmur ve yağmur ile rüzgarın ortak etkisi sonucunda dinlenme davranışında \%50 oranında azalma meydana geldiğini bildirmiştir. Aynı araştırmada davranışlar üzerinde tek başına rüzgarın etkisinin, rüzgar ile yağışın ortak etkisinden daha düşük olduğunu bildirmiştir. Uzal, (2008), aşırı soğuk havalarda hayvanın fiziksel aktivitesi ve yem tüketimi artmasına bağlı olarak hayvanların dinlenme süresinin azaldığını ve ayakta kalma süresinin artığını bildirmiştir. Aynı çalışmada, düşük çevre sıcaklığında ve sslak zeminde yatan hayvanların vücuttan gizli 1s1 kaybı durumunda kendi 1S1 dengesini sağlamak için yatmak yerine ayakta kalmayı tercih ettiklerini ve ayakta kalma süresinin uzamasıyla da yem yeme süresinin artı̆̆ Gebremariam, (2019) soğuk havaya maruz kalan sığırların vücut rezervlerini ve vücut sıcaklıklarını korumak için daha fazla enerjiye ihtiyaç duyduklarını ve yem miktarının arttırılması ile soğuk stresinin etkisinin belli bir düzeye kadar hayvanlar tarafindan tolere edilebildiğini bildirmişlerdir.

$\mathrm{Bu}$ araştırmada, iklimsel faktörlerden yağış miktarının ve soğuk stres indeksinin yürüme süresiyle ilişkili olduğu, yağış ve soğuk stres indeksindeki artışa paralel olarak yürüme süresinde de artış meydana geldiği belirlenmiştir. $\mathrm{Bu}$ sonuca benzer olarak Borshch vd., (2020) barınak olmadan açıkta otlatılarak yetiştirilen sığırların serbest gezinmeli barınaklarda yetiştirilen sığırlara oranla hareket etme sürelerinin daha fazla olduğu ve hayvanların soğuk stresin etkisini azaltmak için özellikle yağışlı havalarda sıcak, korunaklı ve rahat bir yer bulmaya çalışarak hareketlerini artırdıklarını bildirmişlerdir. Buna karşın Endris \& Feki, (2021) serbest gezinmeli açık barınaklarda yetiştirilen sığırların kış mevsiminde buzlu yüzeylerde ve donmuş gübrenin oluşturduğu sert düzensiz zeminlerde hareket etmeyi tercih etmediklerini, bu nedenle hareket sürelerinde azalma olduğunu bildirmişlerdir. Hanninen vd., (2003) ise buzağılar üzerinde yaptıkları araștırmada yürüme süresinin (hareket etme) kapalı barınaklarda yetiştirilen buzağılarda, açıkta yetiştirilen buzağılara oranla daha fazla sürdüğünü, fakat bu farklılığın istatistiksel olarak önemsiz olduğunu bildirmişlerdir.

Sonuç olarak bu araştırmada, iklimsel faktörlerin ve soğuk stresinin hayvan davranışları üzerinde etkili olduğu, özellikle hayvan refahının önemli bir göstergesi olan dinlenme davranışının rüzgar hızının düşük olduğu sıcak dönemlerde daha fazla sürdüğü belirlenmiştir. Ayrıca, düşük çevre sıcaklığının hayvanların yem yeme süresinde, yağış ve soğuk stresinin ise yürüme süresinde artış meydana getirdiği belirlenmiştir. Süt sığırı yetiştiriciliğinde iklimsel faktörlerin ve soğuk stresinin hayvanlar üzerindeki olumsuz etkilerini giderilebilmek için hayvan davranışlarının takip edilmesi ve akabininde sürü yönetiminde düzenlemelerin yapılmasının yararlı olacağı sonucuna varılmıştır. 


\section{TEŞEKKÜR}

Araştırmada iklimsel faktörlerin temininde yardımcı olan Merzifon Meteoroloji İstasyon Müdürlüğüne teşekkür ederiz. $\mathrm{Bu}$ araştırma, OMU Bilimsel Araştırma Projeleri Komisyonu tarafından desteklenmiştir (PYO.VET.1904.20.001).

\section{KAYNAKLAR}

Angrecka, S. \& Herbut, P. (2015). Conditions for cold stress development in dairy cattle kept in free stall barn during severe frosts. Czech Journal of Animal Science, 60(2), 81-87.

Borshch, A.A., Ruban, S., Borshch, A.V . \& Babenko, O. (2019). Effect of three bedding materials on the microclimate conditions, cows behavior and milk yield. Polish Journal of Natural Sciences, 34(1), 19-31.

Borshch, O., Ruban, S., Gutiy, B., Sobolev, A., Kosior, L., Fedorchenko, M., Kirii, A., Pivtorak, Y., Salamakha, I., Hordiichuk, N., Hordiichuk, L., Kamratska, O. \& Denkovich, B. (2020). Comfort and cow behavior during periods of intense precipitation. Ukrainian Journal of Ecology, 10(6), 98-102. DOI: 10.15421/2020_265

Bryant, J.R., López-Villalobos, N., Pryce, J.E., Holmes, C.W. \& Johnson D. L. (2007). Quantifying the effect of thermal environment on production traits in three breeds of dairy cattle in New Zealand. New Zealand Journal of Agricultural Research, 50(3), 327-338.

Davis, M.S., Mader, T.L., Holt, S.M. \& Parkhurst, A.M. (2003). Strategies to reduce feedlot cattle heat stress: Effects on tympanic temperature. Journal of Animal Science, 81(3), 649-661.

Donnelly, J.R. (1984). The productivity of breeding Ewes grazing on Lucuerne or grass and clover pasture on the table lands of Southern Australia III* lamb mortality and weaning percent age. Australian Journal Agricultural Research, 35(5), 709-721.

Endris, M. \& Feki, E. (2021). Review on Effect of Stress on Animal Productivity and Response of Animal to Stressors. Journal of Animal \& Veterinary Advances, 20(1), 1-14.

Girma, F. \& Gebremariam, B. (2019). Review on Effect of Stress on Production and Reproduction of Dairy Cattle. Journal of Scientific \& Innovative Research, 8(1), 29-32.

Graunke, K.L., Schuster, T. \& Lidfors, L.M. (2011). Influence of weather on the behaviour of outdoor- wintered beef cattle in Scandinavia. Livestock Science, 136(2-3), 247-255.

Hanninen, L., Hepola, H., Rushen, J., De Passille, A.M., Pursiainen, P., Tuure, V. M., Syrjälä-qvist, L., Pyykkönen, M. \& Saloniemi, H. (2003). Resting behaviour, growth and diarrhoea incidence rate of young dairy calves housed individually or in groups in warm or cold buildings. Acta Agriculturae Scandinavica, Section A-Animal Science, 53(1), 21-28.

Kaygusuz E. (2020). Açık barınaklarda yetiştirilen Simmental ineklerinde soğuk stresinin süt verimi, süt bileşimi ve bazı davranış özelliklerine etkisi. Yüksek Lisans Tezi, Ondokuz Mayıs Üniversitesi Lisansüstü Eğitim Enstitüsü. Samsun, Türkiye, $39 \mathrm{~s}$.

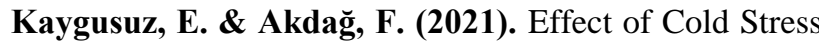
on Milk Yield, Milk Composition and Some Behavioral Patterns of Simmental Cows Kept in Open Shed Barns. Kocatepe Veterinary Journal, 14(3), 351-358.

Koç H.U. \& Uğurlu, M. (2019). Süt sığırlarında 1S1 stresinin verim özellikleri üzerine etkisi. Lalahan Hayvancılık Araştırma Enstitüsü Dergisi, 59(1), 30-35.

Könyves, T., Zlatkovic, N., Memisi, N., Lukac, D., Puvaca, N., Stojsin, M., Halász, A. \& Miscevic, B. (2017). Relationship of temperature-humidity index with milk production and feed intake of holstein-frisian cows in different year seasons. The Thai Journal of Veterinary Medicine, 47(1), 15-23.

Mader, T.L., Johnson, L.J. \& Gaughan, J.B. (2010). Components of the Comprehensive climate index. Journal of Animal Science, 88, 2153-2165.

NRC. (1981). Effect of enviroment on nutrient requirements of domestic Animals. National Acad. Pres. Washington. D.C.

Sasaki, Y., Uematsu, M., Kitahara, G. \& Osawa, T. (2016). Reproductive performance of Japanese Black Cattle: Association with herd size, season, and parity in commercial cow-calf operations. Theriogenology, 86(9), 2156-2161.

Schütz, K.E., Clark, K.V., Cox, N.R., Matthews, L.R. \& Tucker, C.B. (2010). Responses to short-term exposure to simulated rain and wind by dairy cattle: time budgets, shelter use, body temperature and feed intake. Animal Welfare, 19(4), 375-383.

Tullo E., Mattachini G., Riva E., Finzi A., Provolo G. \& Guarino M. (2019). Efects of Climatic Conditions on the Lying Behavior of a Group of Primiparous Dairy Cows. Animals, 9(11), 869. 